\title{
Global Service-Learning: A Systematic Review of Principles and Practices
}

Jason K. Hawes

University of Michigan, USA

Rebecca Johnson

Lindsey Payne

Christian Ley

Purdue University, USA

Caitlin A. Grady

The Pennsylvania State University, USA

Jennifer Domenech

Indiana Department of Natural Resources, USA

Carly D. Evich

Andrew Kanach

Allison Koeppen

Purdue University, USA

\section{Kirsten Roe}

Audrey Caprio

The George Washington University

Jessica Puente Castro

Paige LeMaster

Ernest R. Blatchley

Purdue University, USA

\section{Recommended Citation}

Hawes, J. K., Johnson, R., Payne, L., Ley, C., Grady, C. A., Domenech, J., Evich, C. D., Kanach, A., Koeppen, A., Roe, K., Caprio, A., Puente Castro, J., LeMaster, P., \& Blatchley, E. R. (2021). Global service-learning: A systematic review of principles and practices. International Journal of Research on Service-Learning and Community Engagement, 9(1), Article 11. https://doi.org/10.37333/001c.31383 


\section{Global Service-Learning: A Systematic Review of Principles and Practices}

\author{
Jason K. Hawes, Rebecca Johnson, Lindsey \\ Payne, Christian Ley, Caitlin A. Grady, \\ Jennifer Domenech, Carly D. Evich, Andrew \\ Kanach, Allison Koeppen, Kirsten Roe, \\ Audrey Caprio, Jessica Puente Castro, \\ Paige LeMaster, and Ernest R. Blatchley
}

Global service-learning brings students, instructors, and communities together to support learning and community development across borders. In global service-learning, practitioners act at the intersection of two fields: servicelearning and international development. Critical scholarship in all service-learning and international development has highlighted the tensions inherent in defining and tracking "success" in community development. In response, service-learning and international development have turned considerable attention to documenting project characteristics, also known as best practices or success factors, that support equitable, sustainable community development. This article presents a systematic synthesis of these fields' best practices in the context of global service-learning. The authors propose 18 guiding principles for project design to support practitioners in creating and maintaining justiceoriented, stakeholder-driven projects. The authors compare these principles to emerging best practices in global service-learning and assess the contribution of service-learning and international development research to informing the future of the field.

Keywords: culture, global service-learning, guiding principles, international development, project management

\section{El aprendizaje-servicio global: un estudio sistemático de principios y prácticas}

\author{
Jason K. Hawes, Rebecca Johnson, Lindsey \\ Payne, Christian Ley, Caitlin A. Grady, \\ Jennifer Domenech, Carly D. Evich, Andrew \\ Kanach, Allison Koeppen, Kirsten Roe, \\ Audrey Caprio, Jessica Puente Castro, \\ Paige LeMaster, y Ernest R. Blatchley
}

El aprendizaje-servicio global conecta al profesorado, al estudiantado y a las diferentes comunidades para fomentar el desarrollo comunitario y el aprendizaje transfronterizo. En el aprendizaje-servicio global, los practicantes operan en la intersección de dos campos: el de aprendizaje-servicio y el de desarrollo internacional. El corpus crítico ha subrayado las tensiones inherentes en torno a la definición y evidencia del término 'éxito' en el desarrollo comunitario. Como respuesta, el servicioaprendizaje y el desarrollo internacional se han enfocado considerablemente en la documentación de las características de aquellos proyectos (también llamadas "factores de éxito" o "mejores prácticas") que promueven un desarrollo comunitario sostenible e inclusivo. El presente artículo constituye un resumen sistemático de las mejores prácticas del campo en el contexto del servicio-aprendizaje global. Los autores proponen dieciocho principios para apoyar a los practicantes a la hora de crear y mantener proyectos incluyentes y dirigidos por todas las partes interesadas. Dichos autores comparan estos principios con prácticas innovadoras en aprendizaje-servicio global y evalúan la contribución de la investigación relativa al aprendizaje-servicio y al desarrollo internacional en el futuro del campo.

Palabras clave: cultura, aprendizaje-servicio global, principios guí, desarrollo internacional, gestión de proyectos

Editors' Note: Translation by Maria Fernandez Cifuentes

Department of Languages, Literatures, and Cultures

University of North Florida, USA 
Global service-learning (GSL) is a course-based form of education in which students, instructors, and community members partner on community- development initiatives, often across borders. Based in the broader legacy of service-learning, these partnerships support student learning, cultivate personal development, and hone cultural skills while empowering communities to take an active role in planning and implementing development efforts that emerge from the partnership (Eyler et al., 2001; Hartman et al., 2018). Global service-learning is differentiated from traditional service-learning by its focus on working in other countries or significantly different cultural contexts (e.g., work by students at a historically white university with tribal groups on a reservation-Hartman et al., 2018, Chapter 1).

Integrating student-centric service and cross-cultural community development, GSL is situated at the intersection of two key fields engaged in community development: service-learning (SL) and international development (ID). This paper seeks to understand the implications of that intersection and to assess lessons learned in those fields to inform the continued development of GSL. To do so, we present a systematic review and synthesis of best practices in SL and ID - the first such review to assess principle and practice across the two fields. Through this synthesis, we generate 18 principles of practice informed by SL and ID that warrant further exploration in the context of GSL. To better understand the particular sets of trials and triumphs that have led to these best practices, we begin by exploring the legacies of ID and SL.

The modern field of international development emerged in the post-WWII era as the rebuilding of Europe created actors such as the World Bank, United Nations, World Health Organization, and International Monetary Fund (Gorman, 2014). The field has been profoundly shaped by its connection to the post-colonial and Cold War periods (Gorman, 2014; Mathews-Schultz, 2020), and the political economy of development has strong ties to the colonial period (Kothari, 2005). Development has traditionally revolved around the export of Western technologies, economic models, and governance approaches to nonWestern states (Sylvester, 1999). Given this, it is impossible to discuss ID without reckoning with pervasive neo-colonial practices and attitudes that shaped the field and persist today (Chapman, 2018); in this, the field parallels service-learning (de Oliveira Andreotti \& de Souza, 2012). Despite the traditional narrative of economic and political empowerment, it is clear that historic neo-colonial practices in ID often led to economic stagnation and livelihood degradation that are the subject of today's development projects (Chapman, 2018). Many in the field today attempt to distance themselves from these legacies, and at the core of international development is a hope for supporting infrastructures, institutions, and services in countries and communities, which can be used to improve livelihoods and (at least in the dominant neoliberal model of development) better access the global economy (Chapman, 2018). Modern international development is broadly identified with work aimed at addressing the complex issues outlined by the United Nations' Sustainable Development Goals. This has pulled the field away from a project-centric model of implementation and evaluation (Conlin \& Stirrat, 2008), but a number of project-oriented best practices have still emerged (Khang \& Moe, 2008).

Service-learning is a form of experiential education in which students engage in a service activity that directly addresses a community need while participating in intentional, structured reflection (Jacoby, 2015; Kendall, 1990). Reflection is essential for developing students' understanding of societal structures that drive the community challenges they are addressing. In this regard, reflection emphasizes another key element of service-learning: reciprocity and an intentionality toward balancing community outcomes and student learning (Furco, 1996).

The founders of service-learning, aware of the structural nature of the community challenges they addressed, carried with them a social change agenda (Kendall, 1990). However, as practices have spread and evolved, the field has critically assessed its own praxis, and many key scholars are calling for a shift from traditional service-learning approaches towards critical ones. According to Mitchell, "Without the exercise of care and consciousness, drawing attention to root causes of social problems, and involving students in actions and initiatives addressing root causes, service-learning may have no impact beyond students' good feelings" (Mitchell, 2008, p. 51). This "thin reciprocity," or failure to balance student learning outcomes and community outcomes for the mutual benefit of both partners, embodies technocratic engagement versus democratic engagement (i.e., going beyond the activity and placing emphasis on process and purpose) (Doughty, 2020; Morton, 1995; Saltmarsh et al., 2009). 
Critical service-learning has an "explicit social justice aim" and, according to Mitchell (2008), has three main elements: a social change orientation, efforts to redistribute power, and development of authentic relationships (p. 50). A social justice approach draws attention to the root of societal problems focusing on social responsibility and community challenges. In contrast, traditional service-learning can serve to highlight social divides and hierarchies between groups. Beyond this, critical justice-oriented approaches make space for explicitly anticolonial lenses (VanLeeuwen et al., 2017). It also requires the critical servicelearning practitioner to identify as a social change agent and to work through this identity (Latta et al., 2018). Students, instructors, and community partners must confront assumptions and stereotypes, acknowledge and seek to challenge power differentials, and develop relationships based upon connection, shared understanding, respect, and trust. Keeping these elements in mind, service-learning can be "transformative for the well-being of communities and ... the civic, academic and workforce development of students" (Mitchell \& Donahue, 2017, p. 466). Based on extensive evidence of educational benefits of service-learning and cross-cultural, international programs (Eyler et al., 2001; Hartman et al., 2018; Kiely, 2004), this review takes the normative position that the continued advancement of socially just GSL is a worthwhile pursuit.

Scholars in both international development and service-learning are conscious of troubling rates of program failure (Grady et al., 2014; Hartman et al., 2018), which has led to research focused on monitoring, evaluation, and program redesign (Ika et al., 2012; Lawler, 2011), as well as tools for assessing servicelearning community-campus partnerships (e.g., Model of Social Change, TRES Framework, SOFAR Model - see Bringle et al., 2012; Kniffin et al., 2020; Sgoutas-Emch \& Guerrieri, 2020). Similarly, a number of critiques of GSL projects point out the potential for tremendous community damage in poorly designed GSL (Hartman et al., 2018; Illich, 1968). As GSL becomes more common (Hartman \& Chaire, 2014; Jacoby, 2015), GSL scholars will benefit from observing the best practices and lessons learned in international development and service-learning.

GSL opportunities offer promise for both hope (when done well) and harm (when poorly executed). These programs establish inherently mixed incentives, where the prescribed outcomes, community development and student learning, are not mutually guaranteed (Hartman et al., 2018). GSL must always be viewed as both a pedagogical method and a strategy for community development, and it must be planned and evaluated with these "dual purposes" in mind (Hartman et al., 2018, p. 130). In the service-learning literature, however, student learning outcomes are well known, while less is known regarding faculty outcomes and even less about community impacts (Clayton et al., 2012a, 2012b). This scattered evidence of community outcomes thus warrants collection and re-evaluation in the context of service-learning across borders.

One noteworthy effort to support the dual purpose of student and community outcomes is found in Community-Based Global Learning, the 2018 book by Hartman, Kiely, Boettcher, and Friedrichs. The book provides a synthesis of service-learning, global service-learning, and the authors' own experiences. Hartman and colleagues suggested a shift in terminology from global service-learning to community-based global learning (CBGL) to move the focus away from service and towards learning, partnership, and community development. In particular, they highlighted the deficit implied in a service framing, opting instead for a partnership model based on "shared strengths" (p. 5).

Although we choose to retain the original phrase for consistency with the literature we review, Hartman and colleagues' (2018) emphasis on equity from language to action highlights the role of critical perspectives (i.e. the importance of work conscious of "its own social origins and perspectives" [Horkheimer, 1972, as cited in Gregory et al., 2011, p. 125]) in advancing GSL/CBGL. For example, Hartman et al. also stress the use of the word global instead of international for its attention to "ethical global engagement" whether the students cross national borders or not (p. 18). For this reason, we follow Hartman et al. in the use of the term global, despite use of the term international service-learning in older scoping of the field (Bringle \& Hatcher, 2011; Kiely \& Kiely, 2006). In keeping with this critical lens, we acknowledge the role that our positions as educators in the United States have played in our review and synthesis. While reflecting on how this position has affected our findings, we have sought to simultaneously 
draw on our own experiences and let the experiences of others speak for themselves throughout this article (see Tables 2-5).

While the Hartman book should be considered essential reading in the field, no work to date offers a systematic synthesis of best practices in ID and SL that support just, effective community development interventions in GSL. In response, this article employs a systematic literature review and thematic synthesis of those two bodies of literature: best practices for community development in service-learning and in international development. From this synthesis, this article presents a set of 18 guiding principles that can be used to guide GSL practitioners. In light of the incredible diversity of GSL projects, this set of principles does not contain strictly structuring frameworks but rather is designed to draw attention to important questions of program design and evaluation. We find that four thematic areas emerge, which emphasize the key dimensions of best practice in GSL: (1) Partnership Formation Principles, (2) Course Design Principles, (3) Project Implementation Principles, and (4) broadly applicable Core Principles. GSL as a whole must reflect on how these components might be optimized, and ongoing conversations in ID and SL should inform this reflection.

\section{Methods}

Systematic literature reviews employ strict inclusion and review criteria for the purposes of analyzing a body of literature with minimal bias and maximal transparency (Dixon-Woods, 2010). Early approaches to systematic review were criticized as oversimplifying complex bodies of literature, a challenge that prompted novel framings of systematic review which foregrounded qualitative complexity (Davies et al., 2013). This review adopts a variation on the thematic synthesis approach delineated by Thomas and Harden (2008), seeking to account for the context-driven nature of ID and SL assessments. This process takes place in four stages: abstract review, line-by-line article review, descriptive coding for themes, and analytical synthesis and framework development (Thomas \& Harden, 2008).

\section{Abstract Review: Screening of Documents}

We used Thomson Reuters Web of Science to identify relevant "best practices" literature on ID and SL. The search method for ID was TOPIC: (("success* factor*" OR "best practic*" OR "framework") AND TOPIC: ("internat* dev*"). The parallel search method for SL was TOPIC: ("success* factor*" OR "best practic*" OR "framework") AND TOPIC: ("serv* learn*"). We specified no date range and included only English-language, peer-reviewed articles. We extracted 488 ID articles and 228 SL articles in September 2018. A number of articles have been published under these criteria since then. Although we have sought to reference relevant updates where useful, the long histories of service-learning and international development give us confidence that the synthesized principles remain relevant.

Two individuals were assigned to each of the 716 article abstracts. Each pair used the Rayyan Abstract Review online platform to submit review results, blind of their counterpart's suggestions (Ouzzani et al., 2016). Each coder suggested inclusion or exclusion, listed their certainty (low, medium, or high) and provided an explanation in the case of exclusion. Preliminary rounds of coding and group meetings were used to refine inclusion and exclusion criteria, and coders agreed on inclusion or exclusion of $65 \%$ of the abstracts. For the remaining $35 \%$ of the abstracts, conflicts were resolved by committee consensus, with $3-$ 4 coders collectively assessing and discussing each abstract. The final list of reviewed articles, as well as final inclusion and exclusion criteria, is available in the associated online repository.

\section{Article Full-Text Review: Data Extraction}

Qualtrics survey software was used to compile full-text reviews. Each coder reviewed approximately 15 articles, extracting success factors, best practices, and frameworks of interest. The extracted excerpts were separated into three major categories, defined as follows: The first two categories were two different types of factors (a combination of success factors and best practices). We defined factors as project components or characteristics that were highlighted as driving success (success as defined by the authors of each article). 
Factors were identified as either primary or secondary. Primary factors included any factors that the article defined, analyzed, or synthesized while offering further construction, analysis, or validation. Secondary factors were those factors for which the article offered no additional construction, analysis, or validation beyond description and citation, in which case both the factor and the article being cited were extracted. Frameworks was defined as any theories or previously constructed frameworks explaining the characteristics of successful projects. Extracted frameworks were not included in the synthesis stage of analysis but were referenced for the final presentation of themes in this article.

An assortment of metadata was also collected for each article, including original classification as ID or SL; type of article (e.g., review); and country of interest. We did not test interrater reliability. Instead, extensive training was conducted for each reviewer; we assessed the potential limitations of this method and accounted for this through the decision to code only for generic success factors instead of constructing an emergent codebook during extraction.

\section{Figure 1}

Stages of the synthesis yielding guiding principles for GSL

\begin{tabular}{|l|l|l|l|l|}
\hline Stage 1 & Stage 2 & Stage 3 & Stage 4 & Stage 5 \\
\begin{tabular}{|l|l|l|l|} 
Collaborative \\
open coding
\end{tabular} & $\begin{array}{l}\text { Individual } \\
\text { code refining } \\
\text { and clarifying }\end{array}$ & $\begin{array}{l}\text { Code } \\
\text { resorting and } \\
\text { collaborative } \\
\text { refining }\end{array}$ & $\begin{array}{l}\text { Secondary } \\
\text { factor coding } \\
\text { and code } \\
\text { simplification }\end{array}$ & $\begin{array}{l}\text { Framework } \\
\text { synthesis }\end{array}$ \\
\hline
\end{tabular}

\section{Synthesis: Coding and Framework Development}

Using these extracted factors, four authors inductively coded for descriptive themes and refined these themes into a guiding principles framework. This was accomplished in a series of iterative coding stages (Figure 1). In Stage 1, three authors conducted by-hand pile-sorting of primary factors, eventually forming a series of overarching themes (e.g., Capacity Building, Stakeholders, Monitoring and Evaluation). In Stages 2 and 3, the same three authors further sorted each of these overarching themes into smaller subcategories - for example, Monitoring and Evaluation, containing (1) Formative Evaluation Methods, (2) Summative Evaluation Methods, and (3) Participatory Success Criteria Development-individually before collaboratively refining the emerging codebook. In Stage 4, the lead author conducted a similar pilesorting exercise for the secondary factors, using these secondary factors and sources to validate the themes that emerged from our primary sample of literature. Finally, the four authors mentioned above collaboratively refined the emergent codebook by binning related codes and adapting phrasing. Through this process, 18 guiding principles emerged, which were further binned into four thematic areas.

\section{Results}

After abstract review, 89 ID and $62 \mathrm{SL}$ articles were retained for full-text review, yielding a final inclusion rate of $21 \%$ (ID: $18 \%$, SL: $27 \%$ ). The disparity in inclusion rates between the two fields was mostly due to the nature of international development as both a policy- and a project-based field. Many international development best practices are not oriented towards project management, but rather towards national or international governance, and these were excluded. 
Full-text review of the remaining 151 articles produced 744 primary factors and 233 secondary factors. A total of 105 articles included primary factors, and 70 included secondary factors, while 31 articles contained neither (Table 1). Of 19 international development articles that included neither primary nor secondary factors, about half were theoretical interventions lacking applied commentary, while most remaining were evaluations of specific interventions or technologies. Of 12 service-learning articles that produced no factors, almost all focused exclusively on student learning outcomes.

\section{Table 1}

Review Summary

\begin{tabular}{|c|c|c|c|c|c|}
\hline Field & $\begin{array}{l}\text { Abstracts } \\
\text { Reviewed }\end{array}$ & $\begin{array}{l}\text { Full-texts } \\
\text { Reviewed }\end{array}$ & $\begin{array}{l}\text { Principles } \\
\text { Extracted }\end{array}$ & $\begin{array}{l}\text { Countries Represented } \\
\text { (top 5) }\end{array}$ & $\begin{array}{l}\text { Project types } \\
\text { (top 5) }\end{array}$ \\
\hline $\begin{array}{l}\text { Serv. } \\
\text { Learn. }\end{array}$ & 228 & 62 & 326 & $\begin{array}{l}\text { USA (most common, } \\
\text { often the home of } \\
\text { educational institution); } \\
\text { others included Australia, } \\
\text { Austria, China, Cyprus, } \\
\text { Kenya, South Africa, } \\
\text { Haiti, multiple countries }\end{array}$ & $\begin{array}{l}\text { Healthcare/nursing, } \\
\text { Community } \\
\text { development and } \\
\text { Entrepreneurship, } \\
\text { Auditing, Urban } \\
\text { sustainability, Teaching }\end{array}$ \\
\hline $\begin{array}{l}\text { Intl. } \\
\text { Dev. }\end{array}$ & 488 & 89 & 517 & $\begin{array}{l}\text { Multiple countries (most } \\
\text { common); single-country } \\
\text { studies included } \\
\text { Argentina, Bangladesh, } \\
\text { Morocco, China }\end{array}$ & $\begin{array}{l}\text { Gender equality, } \\
\text { Forestry, Disaster } \\
\text { relief, Water and } \\
\text { sanitation, Civic } \\
\text { engagement and } \\
\text { governance }\end{array}$ \\
\hline
\end{tabular}

Four thematic areas emerged from this framework synthesis: (1) Partnership Principles, (2) Course Design Principles, (3) Project Implementation Principles, and (4) broadly applicable Core Principles. We find that transformative community development cannot be an outcome of GSL without effective practice in all four thematic areas. Therefore, despite the thematic areas described in this synthesis, these guiding principles are intertwined in actual practice.

\section{Partnership Principles}

The thematic area Partnership Principles contains four principles; examples demonstrate the occurrence of these principles in ID and SL (Table 2). The first, advocate for and interface with institution-level infrastructure, encompasses factors that mention the role of institution-level infrastructure, including a support unit, externally engaged professionals, and program facilitators for training instructors, facilitating partnerships, and supporting cultural change at institutions. The principle embrace inter-institutional and inter-program collaboration includes factors related to opportunities for networks of partnerships to leverage existing and overlapping efforts, and they provide consistency and sustainability in local communities. The third principle, identify community partners, develop trust and reciprocal relationships, and implement partnership agreements, incorporates factors that address developing robust, reciprocal community partnerships, fostering trust with community members and leaders, and setting clear expectations of all parties. Finally, the seek participation of administration/authorities outside the project principle consists of factors that suggest a need to engage with administration/authorities on campus and in the community to ensure upfront support and long-term commitment to the project. 
Table 2

Partnership Principles: The Relationships that Form the Foundation of GSL

\section{Partnership Principles}

P1: Advocate for and interface with institution-level infrastructure

International development primary factors $=4$; Service-learning primary factors $=7$

"The manager knows the Civil Service, knows a lot of people, knows how things are done, which gave the project a great deal of credibility.... They have the ability to negotiate with partners at institutional level." (Brière \& Proulx, 2013)
"The second main structural feature is the presence of one or more university-paid staff who link the community into the university by serving as critical bridge persons. Ideally, this staff member should come from and presently reside in the communities with which the university is partnering. She or he should know those communities well." (Ostrander, 2004)

\section{P2: Embrace inter-institutional and inter-program collaboration} International development primary factors $=12$; Service-learning primary factors $=5$

"What we are saying is that these teams of international program participants need to share knowledge, collaborate on topics of interest for all, and, most importantly, do not lose sight of the needs of each collaborating organization." (Cozza \& Blessinger, 2016)
"Composition of relevant partners. The success of the SL projects and the overall case study strongly depends on the composition of relevant partners. A good balance between public city departments, private companies, NGOs or initiatives was necessary to provide an attractive, diverse, and critical platform for dialogue." (Biberhofer \& Rammel, 2017)

\section{P3: Identify community partners, develop trust and reciprocal relationships, and implement partnership agreements \\ International development primary factors $=59 ;$ Service-learning primary factors $=47$}

"Trust surfaces when all parties adhere to written agendas and contracts and conduct all business of the partnership in a transparent manner and when collaborators have opportunities to rely on the other partner in order to achieve positive outcomes." (Cozza \& Blessinger, 2016)
"The theme of reciprocity emerged repeatedly from the data. Participants described the imperative of developing a reciprocal relationship with the community partner and the community." (Pechak \& Thompson, 2009) 


\section{Partnership Principles}

\section{P4: Seek participation of administration/authorities outside the project International development primary factors $=9 ;$ Service-learning primary factors $=3$}

"Political cohesion accounts for the larger political environment in which the project takes place. It recognizes the call for coordinated development efforts by the international development community and the role that local politicians can play in project success." (McConville \& Mihelcic, 2007)
"Partnership: Some programs employ an intermediary to help promote quality experiences. An intermediary typically serves many purposes, including evaluating the clinical site and the CIs, facilitating communication between the university and the international site, and troubleshooting problems on the ground." (Pechak \& Black, 2014)

\section{Course Design Principles}

The thematic area Course Design Principles contains three principles (Table 3). The align scope with curriculum principle consists of factors that focus on aligning the project and course curricula such that the appropriate disciplines are enrolled in the course, and students' skills are meaningfully leveraged and enhanced. The next principle, prepare students for international service-learning, incorporates factors that suggest a need for developing cultural competencies, preparing students for culture shock, and improving students' language skills for host-community placements. The final principle, embrace service-learning best practices in curriculum design, acknowledges the limited scope of this synthesis.

Table 3

Course Design Principles: Enrolling Students and Designing Curriculum

\section{Course Design Principles}

CD1: Align scope with curriculum

International development primary factors $=0$; Service-learning primary factors $=18$

Example Excerpt: International Development Literature
Example Excerpt: Service-Learning Literature

"In the design phase, participants highlighted the importance of appropriate CI and student selection, and typically suggested placing the ICE experience in the latter part of the curriculum. Similar to ISL design, they emphasized the need to explicitly determine learning outcomes that matched the international site." (Pechak \& Black, 2014) 


\section{Course Design Principles}

CD2: Prepare students for international service-learning International development primary factors $=1$; Service-learning primary factors $=5$

"Local Host and Volunteer respondents highlighted the desirability of proficiency in the local language." (Loiseau et al., 2016)
"Preparation of team members academically, socially, culturally, physically, and spiritually needs careful planning and implementation."

(Cone \& Haley, 2016)

\section{CD3: Embrace service-learning best practices in curriculum design}

We did not code for best practices in curriculum design oriented to student learning, as this research is focused on community outcomes. However, these known best practices, studied extensively both in SL and GSL, are essential in serving the "dual purposes" of GSL (Hartman et al., 2018, p. 130). Whereas we present

only principles specifically oriented to community outcomes, this synthesis documented a number of synergies between best practices for learning and best practices for community development, including active student engagement and required reflection.

\section{Project Implementation Principles}

The thematic area Project Implementation Principles contains six guiding principles (Table 4). The first, adopt and coordinate organization, communication, and documentation strategies across stakeholders, profiles the adoption of organization, communication, and documentation strategies that are relevant and acceptable to all stakeholders. The second, implement a flexible, evidence-based design and management system, includes factors related to the variety of design and management systems available as well as the need for these systems to be culturally and disciplinarily specific. Another principle, design goals, measurable objectives, plans, and outputs with tangible, shared impact, incorporates factors that highlight the importance of well-designed, reciprocally beneficial goals, objectives, and plans with measurable, attainable, and tangible outcomes. The fourth principle, recognize and appreciate culture and place, consists of factors ensuring that design of project goals, objectives, and plans gives attention to both culture and place while noting the diversity of cultural interpretations and place relations within a project team. A fifth principle, promote strong, consistent project leadership, includes factors that connected to the role of project leadership in the longevity and effectiveness of projects and partnerships, including consistency and transparency. Lastly, the work within available material and human resources on context-relevant challenges, solutions, and interventions principle includes factors that pay heed to working within the context of host communities and factors that acknowledge constraining resources in the academic institution. 
10 | International Journal of Research on Service-Learning and Community Engagement

Table 4

Project Implementation Principles: Ground Rules for Organizing and Managing Project Partners

\section{Project Implementation Principles}

PI1: Adopt and coordinate organization, communication, and documentation strategies across stakeholders

International development primary factors $=21$; Service-learning primary factors $=8$

\section{Example Excerpt: International Development} Literature

\section{Example Excerpt: Service-Learning Literature}

"Empowerment, two-way communication at all stages of the engagement process and charismatic leadership based on mutual respect and clear communications of roles and responsibilities are vital to improve the likelihood of participants developing understanding of the project aims and philosophy." (Dyer et al., 2014)

"Attention to organization, communication, and documentation is essential." (Long et al., 2001)

PI2: Implement a flexible, evidence-based design and management system International development primary factors $=97 ;$ Service-learning primary factors $=20$

"Project management is not a set of tools, but rather a set of processes that are supported by specific tools. Understanding project management as a set of processes is fundamental for keeping a project under control, because processes are characterized by responsibilities, inputs, planned activities and measurable outputs." (Golini \& Landoni, 2014)
"The concept of structure was the underpinning of establishing ISL. In general, structure among all key players corresponded with larger and seemingly better-implemented programs." (Pechak \& Thompson, 2009)

\section{PI3: Design goals, measurable objectives, plans, and outputs with tangible, shared impact} International development primary factors $=12$; Service-learning primary factors $=5$

"A successful ACIAR forestry research project in PNG was perceived to be one which achieves its specified objectives and outputs, enhances the capacity of partners, facilitates ongoing scientific relationships and networks, and results in tangible scientific impacts and benefits for project stakeholders and local communities." (Bartlett, 2018)
"In order for benefits of a project to be measured, the data must be obtainable and retrievable."

(Voss et al., 2015) 


\section{Project Implementation Principles}

\section{PI4: Recognize and appreciate culture and place} International development primary factors $=20$; Service-learning primary factors $=22$

"Ensuring that evaluators are familiar with local evaluation contexts, cultures and associated sensitivities, and tailoring tone and discourse accordingly. Ideally, a local evaluation partner would be best placed for this. Our experience suggests that external evaluators should share experience of previous work within different country contexts, with those being evaluated and local collaborators." (Marjanovic et al., 2017)
"This includes pre-trip briefing to diminish culture shock, daily briefing while in-country to prepare more effectively for a particular area or type of service, nightly debriefing to process issues as they arise, and post-trip debriefing to deconstruct and contextualize student experiences and enhance personal and professional growth." (Haley \& Cone, 2016)

PI5: Promote strong, consistent project leadership

International development primary factors $=23$; Service-learning primary factors $=10$

"This finding shows that the project manager's leadership style plays an important part in project success. Essentially, a transformational project manager motivates and inspires team members towards a holistic conception of project success, characterized by efficiency, effectiveness, and stakeholder satisfaction." (Aga et al., 2016)
"The make-up of the team is important, particularly leadership by appropriately skilled faculty leaders." (Cone \& Haley, 2016)

PI6: Work within available material and human resources on context-relevant challenges, solutions, and interventions

International development primary factors $=26$; Service-learning primary factors $=12$

"The project was therefore keeping the process in line with key success factors, by ensuring appropriate resource availability, costeffectiveness and the integration of local farming expertise and technical knowledge from the consultancy." (Dyer et al., 2014)
"Availability of resources (time for students): From a student perspective, the SL projects are, by their very nature, more involved compared to traditional, library-based semester projects, and may thus be received with apprehension by some students." (Schoenherr, 2015) 


\section{Core Principles}

The final thematic area, Core Principles, contains attributes applicable to all aforementioned areas. This category contains five principles (Table 5). The first, attend to diversity in project team and community, includes factors that acknowledge students', instructors', and community members' unique experiences, identities, and expertise; responsibilities of project leaders to ensure just, diverse teaming efforts; and awareness of power structures. The principle emphasize team construction, team building, and team capacity building includes factors that pertain to team relationships, capacity building, composition, and skills in working with outside stakeholders. The third principle, employ interdisciplinary, critical, and stakeholder-driven project planning and evaluation, incorporates factors that emphasize the integration of critical perspectives in project planning and evaluation and account for diverse stakeholder perspectives on community needs and outcomes. The fourth principle, identify shared goals and promote ownership and commitment across stakeholders, encompasses factors that highlight the importance of ownership and goals shared by the academic team and diverse community groups. Principle 5, prioritize sustained commitments, regular site visits, and ongoing participation and dialogue with community, consists of factors that mention sustained commitments between an academic institution and a community as well as the necessity for regular visits and effective debriefing among instructors, student leaders, and community partners.

Table 5

Core Principles: Connecting GSL Partnerships, Course Design, and Project Management

\section{Core Principles}

C1: Attend to diversity in project team and community

International development primary factors $=27$; Service-learning primary factors $=4$

\section{Example Excerpt: International Development Literature \\ Example Excerpt: Service-Learning Literature}

"This has led the authors to consider an approach to community level engagement and decisionmaking which recognizes intra-community diversity, promotes trust building through neutral facilitating, seeks to understand social group priorities and visions of sustainability, and to begin developing a conceptual framework that reflects this approach." (Whitton et al., 2015)
"Borrowing from the methods and concepts of cultural anthropology promotes an ability to learn through experience - through active participation and critical observation - how to appropriately interact and develop relationships with people of diverse backgrounds. These methods allow practitioners to learn about the communities they serve, including the critical ability to listen and understand issues from the perspective of local people in those communities." (Flinn, 2011)

\section{C2: Emphasize team construction, team building, and team capacity building International development primary factors $=56$; Service-learning primary factors $=13$}

"Team Project management capacity: team cohesion and trust." (Nanthagopan et al., 2016)
"Interdisciplinary student group composition. A rather clear outcome of the case study is the great advantage of interdisciplinary student group composition. This has proven as a real benefit for the working process, the creative output of the projects and of and of course for the SL partners." (Biberhofer \& Rammel, 2017) 


\section{Core Principles}

C3: Employ interdisciplinary, critical, and stakeholder-driven project planning and evaluation International development primary factors $=88$; Service-learning primary factors $=43$

"Investing time and effort in responding to criticism. Although this appears obvious, regular engagement with criticism (e.g., on issues related to time pressures and prioritization), and clarity and openness in communication on how issues were being addressed were particularly important to establish relationships of trust." (Marjanovic et al., 2017)
"The evaluation plan is as important as the planning and management aspects of a servicelearning project. To guide data collection and analysis, the evaluation plan needs to be in place when a project begins." (Long et al., 2001)

C4: Identify shared goals and promote ownership and commitment across stakeholders International development primary factors $=22$; Service-learning primary factors $=13$

"One of the buzz phrases in development work is local ownership. This phrase refers to the importance of the people in a local community placing value on projects in their community, and having a sense of control and ownership of the project." (Gilfillan, 2015)
"To bring to life the conviction that an engaged university forms a partnership with the community it serves, a core group of 4 faculty, including the faculty member that staffs the clinic, meet regularly with members of the community. We believe that the community itself must retain control of its programs and must identify its own needs and priorities. Further, any service provided for a community must reflect the cultural beliefs and practices of its members." (Hamner et al., 2002)

\section{C5: Prioritize sustained commitments, regular site visits and ongoing participation and dialogue with community \\ International development primary factors $=66$; Service-learning primary factors $=34$}

"Community participation [is] a process that fosters empowerment and ownership in community members through direct participation in development decision making affecting the community." (McConville \& Mihelcic, 2007)
"The deep and ongoing engagement and dialogue with practitioners throughout this process can greatly enhance the experience and the critical evaluation of information, while at the same time leading to a more fruitful collaboration for both parties.” (Young \& Maley, 2018) 


\section{Discussion}

This review synthesized best practices in two project-based fields for the benefit of GSL and GSL practitioners. In doing so, the review revealed similarities with existing GSL research; for example, with respect to partnerships, culture, and critical evaluation. However, our work also highlights a number of places where GSL can learn from the older fields of ID and SL, particularly in project management and evaluation.

\section{Sustainable Teams: Who is in the Room?}

The first important parallel between our synthesis and existing GSL literature is in the focus on teams, team members, and their responsibilities to one another and to their communities. These team members are (1) the student participants, (2) the staff and/or faculty instructors, and (3) the community partners. It is important to note that several models of GSL exist in which an institution-affiliated instructor is not the primary coordinator of the project, but many of the principles remain relevant in these alternative contexts (Hartman et al., 2018, pp. 146-147).

Each group of team members plays a unique role in GSL, and identifying individuals suited to these roles can be key to project success. This begins at the onset of project development, with the identification of a faculty or staff project mentor and a community partner (Angeles \& Gurstein, 2000; Furr et al., 2015). Trust and strong relationships formed between instructors and project partners establish the foundation for effective GSL (Biberhofer \& Rammel, 2017). In the study of GSL, this core relationship has been characterized by the "level of collaboration, depth of connections, and ... commitment to ... long-term partnership" (Kiely \& Nielson, 2003, p. 40). A growing body of empirical assessment of GSL has drawn a clear link between the depth and quality of this relationship and the satisfaction of community partners (Hartman \& Chaire, 2014; Kiely \& Nielson, 2003). Given the importance of these relationships, considerable attention has been given in ID, SL, and GSL literatures to the nature of partnership agreements in varying contexts (Hartman et al., 2018). Our findings, supported by author experiences, suggest that the value of written partnership agreements vary by location and cultural context, though clear delineation of roles and expectations is crucial to project success (Pinel \& Urie, 2017). Ultimately, proof of the partnership rests not in agreements, but in long-term commitment to actions in support of the communities involved (Kiely \& Nielson, 2003).

\section{The Intersection of Pedagogy and Project Management}

As an inherently transient population, students will rarely form the backbone for GSL project longevity. However, it is important to highlight the impact these transient populations can have on the community, partnership, and communication. For this reason, careful student recruitment and engagement are fundamental for GSL success (Brière \& Proulx, 2013; Latif \& Williams, 2017; Pechak \& Black, 2014; Welch et al., 2008). Community development requires a diversity of perspectives, and most scholarship agrees that GSL is improved through interdisciplinarity (Biberhofer \& Rammel, 2017; Bridges et al., 2011; Parece \& Aspaas, 2007). Although international development highlights the importance of careful recruitment of team members with experience in country or in the field (Brière \& Proulx, 2013), in GSL this takes the form of careful selection of disciplines and students participating in the interdisciplinary project.

The structure of the GSL course will significantly impact the balance between importance of student selection and importance of student capacity building (Hartman et al., 2018; Jones \& Steinberg, 2011). For example, in GSL conducted primarily by one individual embedded in an organization, effective program screening is essential for student and partner success. On the other hand, GSL programs that support semester-long pre-immersion preparation or multiyear project engagement may better equip students with project-specific skills after they have joined the team. These curricular decisions are central for student outcomes, but the fundamental responsibility of the instructor to the community is to ensure that the individuals or teams executing the project are properly equipped for solution making in the project context. 
This is made more complex by the social and material context of many GSL projects, including cultural, resource, and availability constraints both in host communities and on campus (Ostrander, 2004). Solutions to community development challenges faced in GSL are often limited by this context (Brière \& Proulx, 2013; Ostrander, 2004), which then requires novel solutions sensitive to the places and institutions involved (McConville \& Mihelcic, 2007). It is unsurprising that ID and SL scholars document that success can often be traced back to creative ideation and collaborative problem-solving exercises (Biberhofer \& Rammel, 2017; Nanthagopan et al., 2016). This sort of creativity can be particularly challenging in interdisciplinary projects, where students are asked to employ high-level problem solving that may not coincide with their disciplinary training. On the other hand, this interdisciplinary problem solving is cited as a key learning outcome for students, and interdisciplinarity in solution making has been documented as enhancing community outcomes.

This is consistent with another finding of our synthesis: the potential for a number of synergies to exist between SL instructional best practices and community outcomes. For example, both educational and intervention-level outcomes can be expected to improve when students play a leading role in project planning, design, and implementation (Long et al., 2001; Pinel \& Urie, 2017). This requires high levels of commitment from participating students, and both students and instructors will be asked to devote considerable time and energy to a successful project (Davis, 2015; Schoenherr, 2015); this has led some scholars to indicate that GSL is best suited for elective coursework, not required curriculum (Davis, 2015). Other recent work has highlighted the role of reflection in helping team members question their assumptions, breaking down barriers for creative ideation and community-driven solutions (Cone \& Haley, 2016; Pechak \& Black, 2014; Pinel \& Urie, 2017).

\section{Project Management and Culture: How do GSL Teams Relate to Each Other?}

Effectively organizing groups associated with a GSL project requires attention to the unique requirements of interdisciplinary teaming (Nancarrow et al., 2013) and cross-cultural leadership and management (Dickson et al., 2003; Smith \& Peterson, 2017). We find that the synthesis of ID and SL is largely consistent with known principles of practice in GSL, but that the relationship between project management and culture is deserving of further attention.

As has also been documented in the cross-cultural management and leadership literature, we find that recognition of the fundamental role of culture and place in operation and team outputs underlies team management, communication, and leadership in GSL (Haley \& Cone, 2016; Whitton et al., 2015). Culture, though often cited as both a key and an obstacle to effective teaming, is a diffuse concept that has garnered hundreds of definitions and endless debate (Søderberg \& Holden, 2002). Moreover, simple interpretations of culture, such as homogenous "software of the mind" frameworks that interpret culture as varying in predictable ways across nations and regions, have predominated in research and practice and have been cited as weaknesses in the study of cross-cultural teaming and management (Hofstede, 1980, as cited in Søderberg \& Holden, 2002). Instead, critical scholars argue, unique multicultural environments emerge as a result of interactions among actors in multicultural teams who vary in both their region of origin and their age, ethnicity, and socioeconomic experience. In this dynamic framing, culture is not simply a driver of team outcomes (i.e., a driver of team failure, as often cited), but rather an emergent characteristic of team communication, participant attitudes, and upfront assumptions (Långstedt, 2018). Therefore, team success and failure should not be attributed to "culture," a monolithic obstacle too large for any team or manager to surmount it. Instead, "culture," as it is experienced, emerges from the interactions of team members. Clarity in assumptions, agreement on communication norms, and sensitivity with regard to unintentional slights have all been found to improve the likelihood of effective multicultural teaming (Ibrahim et al., 2020).

This places the onus for cultural competency and effective multicultural teaming on project participants, especially project leaders. Drawing on cross-cultural psychology, leadership experts have identified a distinction between general and specific leadership and management behaviors, arguing that certain general characteristics are more likely to translate across cultural environments than specific actions (Smith \& 
Peterson, 2017). This is also reflected in the ID and SL literatures, where a variety of organization, communication, and documentation strategies have emerged (Golini \& Landoni, 2014; Nanthagopan et al., 2016), despite the fact that no evidence indicates that any of these strategies are inherently superior to another. Most reviews of project management strategies conclude that the most important aspect of project management system development is the fit between the project culture and the management system chosen (Ika \& Donnelly, 2017; Ostrander, 2004).

This emphasis on cultural competence is demanding of instructors but consistent with long-standing emphasis on faculty development in service-learning (Bringle \& Hatcher, 1995; Bringle et al., 1997; Hartman et al., 2018). While classic training materials largely overlook things like instructor cultural competence and implicit bias training, our synthesis highlights these as key for community outcomes. We join a growing community highlighting the importance of culturally competent instructors (Getto \& McCunney, 2016; Wilson et al., 2010). As Gonzalez et al. (2018) pointed out in their study of implicit bias training, the question becomes How can instructors train culturally competent students or create effective cross-cultural spaces if they themselves are not properly equipped?

\section{What can GSL Accomplish?}

The ultimate judge of community-engaged learning is reciprocal accomplishment: Does the project accomplish its goals for all involved? Project goal setting and monitoring begins with community partnership formation but should continue throughout the project. For example, recurring themes in international development evaluation include ownership and commitment across stakeholders (Angeles \& Gurstein, 2000); shared goals that each group of stakeholders finds meaningful and productive (Voss et al., 2015); and close collaboration with community partners and other community stakeholders to ensure the longevity of the intervention (Brière \& Proulx, 2013; Whitton et al., 2015). This focus on collective goal setting is also seen in GSL literature, where lessons learned from largescale, long-term projects have offered insights into goal setting across contexts (Hartman et al., 2018). Similar to clearly delineated roles and responsibilities among project partners, formal or informal deliberate, iterative goal setting establishes a foundation on which to build project plans and interventions (Jones, 2003).

Many international development organizations focus on three-stage implementation adapted from the logical framework developed by USAID - from goals to goal-driven objectives and from objectives to measurable outputs (Golini et al., 2017). This useful heuristic gives names to the key logics of GSL project development and is consistent with so-called "backwards" course design best practice in curriculum development (Wiggins \& McTighe, 2005, p. 14). As teams work to collaboratively identify project goals, they must translate these goals to tangible deliverables and work iteratively to ensure that these deliverables reflect the goals established (Friedman et al., 2016). These deliverables, or project objectives, are then tied to project outputs, at which point their effects can be monitored and evaluated (Curtis, 2001; Levermore, 2011).

It is, however, no simple thing to evaluate success in project-based community development. For decades, ID and SL projects have struggled to evaluate outcomes at both intervention and community levels. At the community level, this is largely because causal linkage between a single community development project and community-level change is all but impossible to ascertain (Bamberger, 2000). This persists, despite the fact that development agencies writ large have attempted to pivot from a project model to a broader vision of development consistent with the Sustainable Development Goals (Conlin \& Stirrat, 2008). Under these conditions, practitioners rely on theories of change to tie their interventions to expected

community outcomes. In their work with community partners, GSL scholars have reported similar calls for theories of change (Hartman et al., 2018). Ultimately, then, most evaluation is conducted at the level of intervention (White \& Raitzer, 2017). Best practices for evaluation of the tangible project outcomes abound (Ika \& Donnelly, 2017). In particular, our synthesis highlights that these evaluations should be interdisciplinary, critical, and stakeholder-driven in nature. This is consistent with critical GSL literature, which has highlighted the importance of diversity and inclusive participation, as well as interdisciplinary perspectives (discussed above) as project planners seek to define "success" (Kiely \& Kiely, 2006). 
Goal-setting and implementation processes should not be assumed to be effective simply because of a participatory effort (Mansuri \& Rao, 2012). Instead, project teams are best served by using critical lenses for assessing their practices and outcomes. Feminist and critical race lenses have served to reveal the unique ways in which sex, gender, and race influence experience of social systems. Similarly, critical lenses should be used to understand the ways that these identities and their intersections determine the experience of interventions proposed by project teams (Mitchell, 2008). The inclusion of feminist and critical race theory as helpful drivers in unwinding complexities associated with influence and interaction across groups is no small task. There are, however, concrete steps that GSL can take to move towards such efforts, including attention to the dynamics of minoritization in host communities, stratified sampling in evaluation efforts, and work to minimize the influence of power dynamics in project design and execution.

\section{Conclusions}

The synthesis presented here showcases the similarities, strengths, and struggles of ID and SL while highlighting guiding principles worthy of note and of further research in the context of GSL. Recognizing an imbalance between attention to student and community outcomes, this work has sought to identify the principles of practice that can support equitable, sustainable community outcomes from GSL projects. Our synthesized framework includes 18 guiding principles in four thematic areas: (1) Partnership Principles, (2) Course Design Principles, (3) Project Implementation Principles, and (4) Core Principles. These guiding principles highlight the need for careful management of sustainable partnerships and strategically constructed teams. The principles also indicate that the individuals in the room, their curated working culture, and their willingness to learn new skills are all instrumental in a successful GSL project. We reiterate the long-standing SL commitment to reciprocity, and we highlight the importance of relationships built on trust, effective communication, and equity in power.

It is imperative that future work in the field of GSL focus on goals that can be accomplished through specific, attainable, and measurable deliverables. These goals and evaluation of these goals should be stakeholder-driven, and practitioners should employ criticality throughout the lifecycle of GSL, paying special heed to the gendered and racialized experiences of community members affected by GSL. No one of these practices on its own is the key to success, and only in combination can principles of partnership, course design, and project implementation yield effective, just community development via GSL.

\section{References}

Aga, D. A., Noorderhaven, N., \& Vallejo, B. (2016). Transformational leadership and project success: The mediating role of team-building. International Journal of Project Management, 34(5), 806818. https://doi.org/10.1016/j.ijproman.2016.02.012

Angeles, L., \& Gurstein, P. (2000). Planning for participatory capacity development: The challenges of participation and North-South partnership in capacity building projects. Canadian Journal of Development Studies / Revue Canadienne d'études du développement, 21(Suppl.), 447-478. https://doi.org/10.1080/02255189.2000.9669926

Bamberger, M. (2000). The evaluation of international development programs: A view from the front. American Journal of Evaluation, 21(1), 95-102. https://doi.org/10/cf4b9s

Bartlett, A. G. (2018). Factors affecting the success of collaborative forestry research in Papua New Guinea. Australian Forestry, 81(2), 116-128. https://doi.org/10/gjs98t

Biberhofer, P., \& Rammel, C. (2017). Transdisciplinary learning and teaching as answers to urban sustainability challenges. International Journal of Sustainability in Higher Education, 18(1), 6383. https://doi.org/10/f9t4dr 
Bridges, D., Davidson, R. A., Odegard, P. S., Maki, I. V., \& Tomkowiak, J. (2011). Interprofessional collaboration: Three best practice models of interprofessional education. Medical Education Online, 16(1), Article 6035. https://doi.org/10.3402/meo.v16i0.6035

Brière, S., \& Proulx, D. (2013). The success of an international development project: Lessons drawn from a case between Morocco and Canada. International Review of Administrative Sciences, 79(1), 165-186. https://doi.org/10/f4s9nt

Bringle, R. G., Clayton, P., \& Price, M. (2012). Partnerships in service learning and civic engagement. Partnerships: A Journal of Service-Learning and Civic Engagement, 1(1), 1-20.

Bringle, R. G., \& Hatcher, J. A. (1995). A service-learning curriculum for faculty. Michigan Journal of Community Service Learning, 2(1), 112-122. https://hdl.handle.net/1805/4591

Bringle, R. G., \& Hatcher, J. A. (2012). International service learning. In R. G. Bringle, J. A. Hatcher, \& S. G. Jones (Eds.), International service learning: Conceptual frameworks and research (pp. 328). Stylus Publishing.

Bringle, R. G., Hatcher, J. A., \& Games, R. (1997). Engaging and supporting faculty in service learning. Journal of Public Service and Outreach, 2, 43-51.

Chapman, D. D. (2018). The ethics of international service learning as a pedagogical development practice: A Canadian study. Third World Quarterly, 39(10), 1899-1922. https://doi.org/10/gjwd3j

Clayton, P. H., Bringle, R. G., \& Hatcher, J. A. (Eds.). (2012a). Research on service learning: Conceptual frameworks and assessments: Communities, institutions, and partnerships. Stylus Publishing.

Clayton, P. H., Bringle, R. G., \& Hatcher, J. A. (Eds.). (2012b). Research on service learning: Conceptual frameworks and assessments: Students and faculty. Stylus Publishing.

Cone, P. H., \& Haley, J. M. (2016). Mobile clinics in Haiti, part 1: Preparing for service-learning. Nurse Education in Practice, 21, 1-8. https://doi.org/10/f9fkg2

Conlin, S., \& Stirrat, R. L. (2008). Current challenges in development evaluation. Evaluation, 14(2), 193208. https://doi.org/10/cnvk4z

Cozza, B., \& Blessinger, P. (2016). Pioneering approaches in university partnerships: An introduction to university partnerships for international development. In University partnerships for international development (Vol. 8, pp. 3-17). Emerald Group Publishing.

Curtis, D. (2001). Finding energy in strategic project management: An essay in honour of Dean Fang. Public Administration and Development, 21(4), 297-307. https://doi.org/10/fbdp8z

Davies, D., Jindal-Snape, D., Collier, C., Digby, R., Hay, P., \& Howe, A. (2013). Creative learning environments in education-A systematic literature review. Thinking Skills and Creativity, 8, 8091. https://doi.org/10.1016/j.tsc.2012.07.004

Davis, J. (2015). Engaging criminal justice students through service learning. Journal of Criminal Justice Education, 26(3), 253-272. https://doi.org/10/gjtk9p

de Oliveira Andreotti, V., \& de Souza, L. M. T. (2012). Postcolonial perspectives on global citizenship education. Routledge.

Dickson, M. W., Den Hartog, D. N., \& Mitchelson, J. K. (2003). Research on leadership in a crosscultural context: Making progress, and raising new questions. The Leadership Quarterly, 14(6), 729-768. https://doi.org/10.1016/j.leaqua.2003.09.002

Dixon-Woods, M. (2010). Systematic reviews and qualitative methods. In D. Silverman (Ed.), Qualitative research: Theory, method and practice (3rd ed., pp. 331-346). SAGE Publications. 
Doughty, J. R. (2020). A narrative study of South African community members' experience with an international service-learning program. International Journal of Research on Service-Learning and Community Engagement, 8(1), Article 16. https://doi.org/10.37333/001c.12661

Dyer, J., Stringer, L. C., Dougill, A. J., Leventon, J., Nshimbi, M., Chama, F., Kafwifwi, A., Muledi, J. I., Kaumbu, J.-M. K., Falcao, M., Muhorro, S., Munyemba, F., Kalaba, G. M., \& Syampungani, S. (2014). Assessing participatory practices in community-based natural resource management: Experiences in community engagement from Southern Africa. Journal of Environmental Management, 137, 137-145. https://doi.org/10.1016/j.jenvman.2013.11.057

Eyler, J., Giles, D. E., Jr., Stenson, C. M., \& Gray, C. J. (2001). At a glance: What we know about the effects of service-learning on college students, faculty, institutions and communities, 1993-2000. Vanderbilt University/Corporation for National Service.

Flinn, J. (2011). Ethnographic methods in nonprofit management. Nonprofit and Voluntary Sector Quarterly, 40(3), 420-434. https://doi.org/10.1177\%2F0899764009346334

Friedman, M. A., Gossett, D. R., Saucedo, I., Weiner, S., Young, M. W., Penco, N., \& Evert, J. (2016). Partnering with Parteras: Multi-collaborator international service-learning project impacts on traditional birth attendants in Mexico. International Journal of Research on Service-Learning and Community Engagement, 4(1). Article 14. https://doi.org/10.37333/001c.29616

Furco, A. (1996). Service-learning: A balanced approach to experiential education. In Corporation for National Service (Ed.), Expanding boundaries: Serving and learning (pp. 2-6).

Furr, S. B., Lane, S. H., Serafica, R. C., \& Hodge, M. A. (2015). Service-learning and interprofessional education in nursing: A critical need. Journal of Christian Nursing, 32(3), 162-167. https://doi.org/10/gjtk9r

Getto, G., \& McCunney, D. (2016). Moving from traditional to critical service-learning: Reflexivity, reciprocity, and place. In A. S. Tinkler, B. E. Tinkler, V. M. Jagla, \& J. R. Strait (Eds.), Servicelearning to advance social justice in a time of radical inequality (pp. 347-358). Information Age Publishing.

Gilfillan, D. (2015). Short- term volunteering and international development: an evaluation framework for volunteer tourism. Tourism Analysis, 20(6), 607-618. https://doi.org/10/gjs95m

Golini, R., Corti, B., \& Landoni, P. (2017). More efficient project execution and evaluation with logical framework and project cycle management: Evidence from international development projects. Impact Assessment and Project Appraisal, 35(2), 128-138. https://doi.org/10.1080/14615517.2016.1239495

Golini, R., \& Landoni, P. (2014). International development projects by non-governmental organizations: An evaluation of the need for specific project management and appraisal tools. Impact Assessment and Project Appraisal, 32(2), 121-135. https://doi.org/10.1080/14615517.2014.894088

Gonzalez, C. M., Garba, R. J., Liguori, A., Marantz, P. R., Diane McKee, M., \& Lypson, M. L. (2018). How to make or break implicit bias instruction: Implications for curriculum development. Academic Medicine: Journal of the Association of American Medical Colleges, 93(11), S74-S81. https://doi.org/10/ghwsr4

Gorman, D. (2014). Britain, India, and the United Nations: Colonialism and the development of international governance, 1945-1960. Journal of Global History, 9(3), 471-490. https://doi.org/10.1017/S1740022814000217 
Grady, C. A., Weng, S.-C., \& Blatchley, E. R. (2014). Potable water: Current status, critical problems, and future perspectives. In T. Younos \& C. A. Grady (Eds.), Potable water: Emerging global problems and solutions (pp. 37-59). Springer International Publishing.

Gregory, D., Johnston, R., Pratt, G., Watts, M., \& Whatmore, S. (2011). The dictionary of human geography. John Wiley \& Sons.

Haley, J. M., \& Cone, P. H. (2016). Mobile clinics in Haiti, part 2: Lessons learned through service. Nurse Education in Practice, 21, 66-74. https://doi.org/10.1016/j.nepr.2016.08.009

Hamner, J. B., Wilder, B., Avery, G., \& Byrd, L. (2002). Community-based service learning in the engaged university. Nursing Outlook, 50(2), 67-71. https://doi.org/10/cwd9pb

Hartman, E., \& Chaire, C. (2014). Market incentives and international volunteers: The development and evaluation of fair trade learning. Journal of Public Scholarship in Higher Education, 4, 31-68.

Hartman, E., Kiely, R. C., Friedrichs, J., \& Boettcher, C. (2018). Community-based global learning: The theory and practice of ethical engagement at home and abroad. Stylus Publishing.

Hofstede, G. H. (1980). Culture's consequences: International differences in work-related values. SAGE.

Ibrahim, H., Abdulai, M., \& Abubakari, A. (2020). Culture and international volunteerism: An analytic study of intercultural interactions between UK and Ghanaian volunteers on the International Citizen Service (ICS) Program. Human Arenas, 3(2), 279-295. https://doi.org/10/gjhbkv

Ika, L. A., Diallo, A., \& Thuillier, D. (2012). Critical success factors for World Bank projects: An empirical investigation. International Journal of Project Management, 30(1), 105-116. https://doi.org/10.1016/j.ijproman.2011.03.005

Ika, L. A., \& Donnelly, J. (2017). Success conditions for international development capacity building projects. International Journal of Project Management, 35(1), 44-63. https://doi.org/10.1016/j.ijproman.2016.10.005

Illich, I. (1968, April). To hell with good intentions. Speech presented at the Conference on InterAmerican Student Projects, Cuernavaca, Mexico.

Jacoby, B. (2015). Service-learning essentials: Questions, answers, and lessons learned. John Wiley \& Sons.

Jones, S. R. (2003). Principles and profiles of exemplary partnerships with community agencies. In B. Jacoby (Ed.), Building partnerships for service-learning (pp. 151-173). Jossey-Bass.

Jones, S. G., \& Steinberg, K. S. (2012). An analysis of international service learning programs. In R. G. Bringle, J. A. Hatcher, \& S. G. Jones (Eds.), International service learning: Conceptual frameworks and research (pp. 89-112). Stylus Publishing.

Kendall, J. C. (1990). Combining service and learning: A resource book for community and public service (Vol. II). ERIC.

Khang, D. B., \& Moe, T. L. (2008). Success criteria and factors for international development projects: A life-cycle-based framework. Project Management Journal, 39(1), 72-84. https://doi.org/10/brk3sw

Kiely, R. (2004). A chameleon with a complex: Searching for transformation in international servicelearning. Michigan Journal of Community Service Learning, 10(2), 5-20.

Kiely, A., \& Kiely, R. (2006). International service-learning: What? Why? How? NAFSA: Association of International Educators 58th Annual Conference, Montreal, Canada. 
Kiely, R., \& Nielson, D. (2003). International service learning: The importance of partnerships. Community College Journal, 39-41.

Kniffin, L., Camo-Biogradlija, J., Price, M. F., Kohl, E., Dickovick, A. D. C., Williams, J., Goodwin, J., Johnson, K. V., Clayton, P. H., \& Bringle, R. G. (2020). Relationships and partnerships in community-campus engagement: Evolving inquiry and practice. International Journal of Research on Service-Learning and Community Engagement, 8(1), Article 15. https://doi.org/10.37333/001c.18586

Kothari, U. (2005). From colonial administration to development studies: A post-colonial critique of the history of development studies. In U. Kothari (Ed.), A radical history of development studies: Individuals, institutions and ideologies (pp. 47-66). Zed Books.

Långstedt, J. (2018). Culture, an excuse?-A critical analysis of essentialist assumptions in cross-cultural management research and practice. International Journal of Cross Cultural Management, 18(3), 293-308. https://doi.org/10.1177\%2F1470595818793449

Latif, K. F., \& Williams, N. (2017). Team effectiveness in non-governmental organizations (NGOs) projects. Evaluation and Program Planning, 64, 20-32. https://doi.org/10.1016/j.evalprogplan.2017.05.004

Latta, M., Kruger, T. M., Payne, L., Weaver, L., \& VanSickle, J. L. (2018). Approaching critical servicelearning: A model for reflection on positionality and possibility. Journal of Higher Education Outreach and Engagement, 22(2), 31-55.

Lawler, J. P. (2011). Critical success factors for partnering with nonprofit organizations on digital technology service-learning projects: A case study. In M. Bowdon \& R. G. Carpenter (Eds.), Higher education, emerging technologies, and community partnerships: Concepts, models, and practices (pp. 106-123). IGI Global. https://doi.org/10.4018/978-1-60960-623-7.ch010

Levermore, R. (2011). Evaluating sport-for-development: Approaches and critical issues. Progress in Development Studies, 11(4), 339-353. https://doi.org/10/dvssm5

Loiseau, B., Sibbald, R., Raman, S. A., Darren, B., Loh, L. C., \& Dimaras, H. (2016). Perceptions of the role of short-term volunteerism in international development: Views from volunteers, local hosts, and community members. Journal of Tropical Medicine, 2016. https://doi.org/10.1155/2016/2569732

Long, A. B., Travis, S. S., Larsen, P., \& Hussey, L. (2001). Organizing, managing, and evaluating service-learning projects. Educational Gerontology, 27(1), 3-21. https://doi.org/10/dksw68

Mansuri, G., \& Rao, V. (2012). Localizing development: Does participation work? World Bank Publications.

Marjanovic, S., Cochrane, G., Robin, E., Sewankambo, N., Ezeh, A., Nyirenda, M., Bonfoh, B., Rweyemamu, M., \& Chataway, J. (2017). Evaluating a complex research capacity-building intervention: Reflections on an evaluation of the African Institutions Initiative. Evaluation, 23(1), 80-101. https://doi.org/10/gf4jqk

Mathews-Schultz, A. L. (2020). The untold history of the United Nations, the US State Department, and organized interests in the postwar era. Social Science History, 44(2), 197-222. https://doi.org/10/gjwd3h

McConville, J. R., \& Mihelcic, J. R. (2007). Adapting life-cycle thinking tools to evaluate project sustainability in international water and sanitation development work. Environmental Engineering Science, 24(7), 937-948. https://doi.org/10.1089/ees.2006.0225 
Mitchell, T. D. (2008). Traditional vs. critical service-learning: Engaging the literature to differentiate two models. Michigan Journal of Community Service Learning, 14(2), 50-65.

Mitchell, T. D., \& Donahue, D. M. (2017). Ideal and real in service learning: Transforming the ideal based on the real. In C. Dolgon, T. D. Mitchell, \& T. K. Eatman (Eds.), The Cambridge handbook of service learning and community engagement (pp. 458-469). Cambridge University Press.

Morton, K. (1995). The irony of service: Charity, project, and social change in service-learning. Michigan Journal of Community Service Learning, 2(1), 19-32.

Nancarrow, S. A., Booth, A., Ariss, S., Smith, T., Enderby, P., \& Roots, A. (2013). Ten principles of good interdisciplinary team work. Human Resources for Health, 11(1), Article 19. https://doi.org/10/gbc6ch

Nanthagopan, Y., Williams, N. L., \& Page, S. (2016). Understanding the nature of project management capacity in Sri Lankan non-governmental organisations (NGOs): A resource based perspective. International Journal of Project Management, 34(8), 1608-1624. https://doi.org/10/f9cnx8

Ostrander, S. A. (2004). Democracy, civic participation, and the university: A comparative study of civic engagement on five campuses. Nonprofit and Voluntary Sector Quarterly, 33(1), 74-93. https://doi.org/10/fvvt9h

Ouzzani, M., Hammady, H., Fedorowicz, Z., \& Elmagarmid, A. (2016). Rayyan-A web and mobile app for systematic reviews. Systematic Reviews, 5(210). https://doi.org/10.1186/s13643-016-0384-4

Parece, T. E., \& Aspaas, H. R. (2007). Reedy Creek cleanup: The evolution of a university geography service-learning project. Journal of Geography, 106(4), 153-161. https://doi.org/10/dwqtss

Pechak, C. M., \& Black, J. D. (2014). Exploring international clinical education in US-based programs: Identifying common practices and modifying an existing conceptual model of international service-learning. Physiotherapy Theory and Practice, 30(2), 94-104. https://doi.org/10/gjtbzx

Pechak, C. M., \& Thompson, M. (2009). A conceptual model of optimal international service-learning and its application to global health initiatives in rehabilitation. Physical Therapy, 89(11), 11921204. https://doi.org/10/fwc56s

Pinel, S. L., \& Urie, R. (2017). Learning reflective planning: the application of participatory action research principles to planning studio design and assessment. Journal of Architectural and Planning Research, 34(1), 32-48.

Saltmarsh, J., Hartley, M., \& Clayton, P. (2009). Democratic engagement white paper. New England Resource Center for Higher Education.

Schoenherr, T. (2015). Service- learning in supply chain management: Benefits, challenges and best practices. Decision Sciences Journal of Innovative Education, 13(1), 45-70. https://doi.org/10/gjtk94

Sgoutas-Emch, S., \& Guerrieri, K. (2020). Utilizing a model of social change to examine and foster equitable, democratic, and mutually beneficial networked community partnerships. International Journal of Research on Service-Learning and Community Engagement, 8(1), Article 14. https://doi.org/10.37333/001c.18786

Smith, P. B., \& Peterson, M. F. (2017). Cross-cultural leadership. In M. J. Gannon \& K. L. Newman (Eds.), The Blackwell Handbook of Cross-Cultural Management (pp. 217-235). John Wiley \& Sons.

Søderberg, A.-M., \& Holden, N. (2002). Rethinking cross cultural management in a globalizing business world. International Journal of Cross Cultural Management, 2(1), 103-121.

https://doi.org/10/cvmv5r 
Sylvester, C. (1999). Development studies and postcolonial studies: Disparate tales of the "Third World." Third World Quarterly, 20(4), 703-721. https://doi.org/10/fsntkf

Thomas, J., \& Harden, A. (2008). Methods for the thematic synthesis of qualitative research in systematic reviews. BMC Medical Research Methodology, 8(45). https://doi.org/10.1186/1471-2288-8-45

VanLeeuwen, C. A., Weeks, L. E., \& Guo-Brennan, L. (2017). Indigenous perspectives on community service-learning in higher education: An examination of the Kenyan context. International Journal of Research on Service-Learning and Community Engagement, 5(1), Article 10. https://doi.org/10.37333/001c.29769

Voss, H. C., Mathews, L. R., Fossen, T., Scott, G., \& Schaefer, M. (2015). Community- academic partnerships: Developing a service-learning framework. Journal of Professional Nursing, 31(5), 395-401. https://doi.org/10/f7t4wt

Welch, C. L., Welch, D. E., \& Tahvanainen, M. (2008). Managing the HR dimension of international project operations. The International Journal of Human Resource Management, 19(2), 205-222. https://doi.org/10.1080/09585190701799754

White, H., \& Raitzer, D. A. (2017). Impact evaluation of development interventions: A practical guide. Asian Development Bank.

Whitton, J., Parry, I. M., Akiyoshi, M., \& Lawless, W. (2015). Conceptualizing a social sustainability framework for energy infrastructure decisions. Energy Research \& Social Science, 8, 127-138. https://doi.org/10/gfpjxi

Wiggins, G. P., \& McTighe, J. (2005). Understanding by design. Association for Supervision and Curriculum Development.

Wilson, A. H., Sanner, S., \& McAllister, L. E. (2010). A longitudinal study of cultural competence among health science faculty. Journal of Cultural Diversity, 17(2), 68-72.

Young, S., \& Maley, M. (2018). Using practitioner-engaged evidence synthesis to teach research and information literacy skills: A model and case study. The Journal of Academic Librarianship, 44(2), 231-237. https://doi.org/10/gjtk9s

\footnotetext{
About the Authors

Jason K. Hawes is a Ph.D. student at the School for Environment and Sustainability, University of Michigan.

Rebecca Johnson is a clinical assistant professor at the School of Nursing, Purdue University.

Lindsey Payne is the director of service-learning and an assistant professor of practice in environmental and ecological engineering at Purdue University.

Christian Ley is an American Society for Engineering Education (ASEE) postdoctoral fellow at the University of Colorado.

Caitlin A. Grady is an assistant professor of civil and environmental engineering, with a joint appointment in the Rock Ethics Institute, at The Pennsylvania State University (Penn State).
} 
Jennifer Domenech, M.S. in Natural Resource Social Science from Purdue University, is an outreach specialist with the Indiana Department of Natural Resources.

Carly D. Evich is a Ph.D. student in the Department of Human Development and Family Studies and a graduate assistant for service-learning at Purdue University West Lafayette.

Andrew Kanach contributed to this work during his Ph.D. program in microbiology at Purdue University.

Allison Koeppen, BSN from Purdue University, currently works as a registered nurse in trauma intensive care.

Kirsten Roe is a subject matter expert and data analyst for Food for the Poor.

Audrey Caprio is a senior program assistant in the Global Health Security Initiative at PATH.

Jessica Puente Castro, MS in Environmental and Ecological Engineering from Purdue University, is an environmental engineer at $3 \mathrm{M}$.

Paige LeMaster, BS in Agricultural Economics from Purdue University, is a paraprofessional at an elementary school in Frankfort, Indiana.

Ernest R. Blatchley III is the Lee A. Rieth professor in environmental engineering at Purdue University, where he holds a joint faculty appointment in the Lyles School of Civil Engineering and the Division of Environmental \& Ecological Engineering.

Corresponding concerning this article should be addressed to Jason Hawes at jasonkhawes@gmail.com or jkhawes@umich.edu. 